\title{
Near-Infrared Spectroscopy
}

OST Reference \#86

Tanks Focus Area

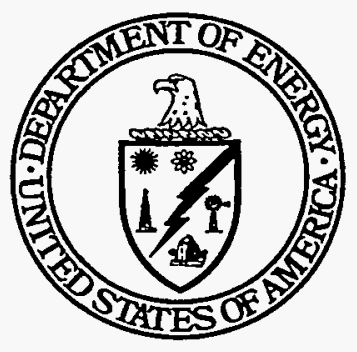

Demonstrated at Hanford Site Hanford, Washington 


\section{DISCLAIMER}

This report was prepared as an account of work sponsored by an agency of the United States Government. Neither the United States Government nor any agency thereof, nor any of their employees, make any warranty, express or implied, or assumes any legal liability or responsibility for the accuracy, completeness, or usefulness of any information, apparatus, product, or process disclosed, or represents that its use would not infringe privately owned rights. Reference herein to any specific commercial product, process, or service by trade name, trademark, manufacturer, or otherwise does not necessarily constitute or imply its endorsement, recommendation, or favoring by the United States Government or any agency thereof. The views and opinions of authors expressed herein do not necessarily state or reflect those of the United States Government or any agency thereof. 


\section{DISCLAIMER}

Portions of this document may be illegible in electronic image products. Images are produced from the best available original document. 


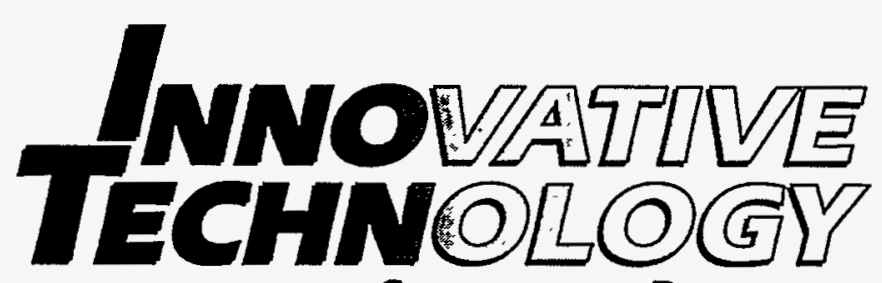

Summary Report

\section{Purpose of this document}

Innovative Technology Summary Reports are designed to provide potential users with the information they need to quickly determine if a technology would apply to a particular environmental management problem. They are also designed for readers who may recommend that a technology be considered by prospective users.

Each report describes a technology, system, or process that has been developed and tested with funding from DOE's Office of Science and Technology (OST). A report presents the full range of problems that a technology, system, or process will address and its advantages to the DOE cleanup in terms of system performance, cost, and cleanup effectiveness. Most reports include comparisons to baseline technologies as well as other competing technologies. Information about commercial availability and technology readiness for implementation is also included. Innovative Technology Summary Reports are intended to provide summary information. References for more detailed information are provided in an appendix.

Efforts have been made to provide key data describing the performance, cost, and regulatory acceptance of the technology. If this information was not available at the time of publication, the omission is noted.

All published Innovative Technology Summary Reports are available on the OST Web site at http://OST.em.doe.gov under "Publications." 


\section{TABLE OF CONTENTS}

1 SUMMARY

page 1

2 TECHNOLOGY DESCRIPTION page 3

3 PERFORMANCE

page 6

4 TECHNOLOGY APPLICABILITY AND

ALTERNATIVE TECHNOLOGIES

page 11

$5 \cos T$

page 12

6 REGULATORY/POLICY ISSUES

page 14

7 LESSONS LEARNED

page 15

\section{APPENDICES}

A References

B Site Descriptions 


\section{SECTION 1}

\section{SUMMARY}

\section{Technology Description}

A near-infrared (NIR) spectroscopy system with a remote fiber-optic probe was developed and demonstrated to measure the water content of high-level radioactive wastes from the underground storage tanks at the Hanford Site in Richland Washington. The technology was developed as a cost-effective and safer alternative to the thermogravimetric analysis (TGA) technique in use as the baseline. This work was supported by the Tanks Focus Area (TFA) within the Department of Energy's (DOE) Office of Science and Technology (OST) in cooperation with the Hanford Tank Waste Remediation System (TWRS) Program.

- A commercially available spectrophotometer was combined with a commercially available remote fiber-optic probe to create the NIR system.

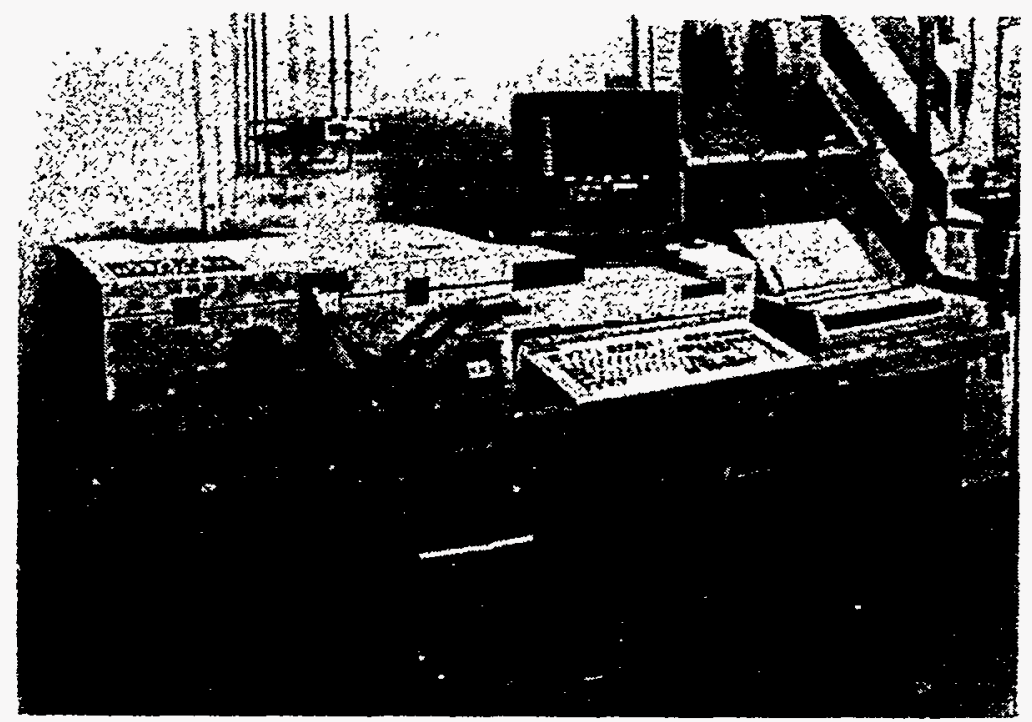

Figure 1. The NIR spectrometer and software require minimal space.

- The NIR system uses a low-power light source to measure optical molecular absorption within a sample. This light beam is passed through fiber-optic cable from the analyzer system to the probe inside a hot cell.

0 The fiber-optic cable uses existing penetrations through the hot cell; these penetrations were designed for such cabling.

$\checkmark$ Samples remain within the hot cell rather than being loaded out for analyses in a fume-hood.

$\checkmark$ Water content is measured without directly contacting the sample.

- The NIR system takes advantage of the NIR optical reflection from a sample to determine total water concentration. Water concentration is determined from the NIR spectra using calibration models based on partial least squares (PLS) numerical analysis methods. Calibration models are built from simulant and real waste standards with known moisture contents.

- The NIR system provides fast, accurate data with relatively little sample preparation.

- The innovation of the NIR system is a rugged fiber-optic probe that can survive the harsh caustic and radiation environment of the samples.

- The NIR system provides real-time moisture data with similar accuracy as TGA or other standard moisture assay methods. 


\section{SUMMARY continued}

\section{Technology Status}

- The NIR probe has been deployed into a hot cell at the Hanford Site, where tank samples are undergoing a number of chemical and physical characterization procedures.

$\checkmark$ The probe is easily handled with hot cell manipulators.

$\checkmark$ NIR moisture data can be obtained from different regions of an extruded core sample of radioactive tank waste and along the total length of a core segment (approximately 48 centimeters in length), providing an indication of core homogeneity.

- Demonstration of the NIR provided accurate measurements on over sixty actual radioactive waste samples.

- The remote fiber-optic probe is compatible with a cone penetrometer, the Light-Duty Utility Arm (LDUA), and other mechanical deployment systems, and is also applicable for use in on-line processing applications.

- The NIR method has been proposed to the Safety Program at Hanford as a replacement for the TGA method.

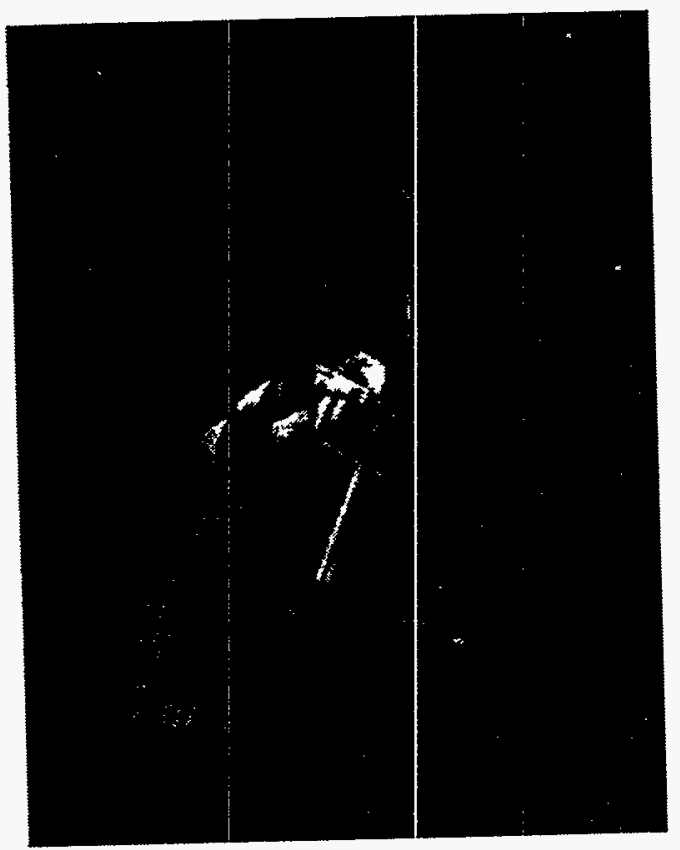

Figure 2. The NIR fiber optic probe can be handled by the LDUA.

\section{CONTACTS}

\section{Technical}

Fred Reich, Principal Investigator, SGN Eurisys Services Corporation, (509) 376-4063.

Dave Dodd, Laboratory Manager, Numatec Hanford Company (NHC), (509) 373-2154.

\section{Management}

Ted Pietrok, Tanks Focus Area Team Lead, Department of Energy, Richland, (509) 372-4546.

Kurt Gerdes, Tanks Focus Area Program Manager, Department of Energy, Headquarters, (301) 903-7289. 


\section{TECHNOLOGY DESCRIPTION}

\section{Background}

Water concentration of the high-level waste (HLW) stored in the underground tanks at the Hanford Site is a critical parameter for the safe storage of radioactive waste (Postma et al. 1994).

- Radioactive waste composition is complex and heterogenous in nature.

- Characterization efforts have identified complex organic (e.g. cyanide, kerosene) and inorganic chemicals (e.g. nitrites, nitrates, hydroxide), as well as high-activity radioactive metals, including cesium, technetium, strontium, and actinides, in the HLW.

0 Scientists have identified that organic or cyanide reactions with the nitrate could potentially produce sufficient energy to release dangerous and hazardous chemicals to the environment.

$\checkmark$ Tank waste with water concentrations greater than 17 weight percent (wt\%) have been shown to be stable even though they may have high levels of organic or ferrocyanide materials (Babad et al., 1995). It is speculated that the water acts as a diluent and reduces or eliminates the potential for exothermic reactions.

\section{Instrument Components}

The NIR system consists of a spectrophotometer and a remote fiber-optic probe connected by fiber-optic cable, as described below.

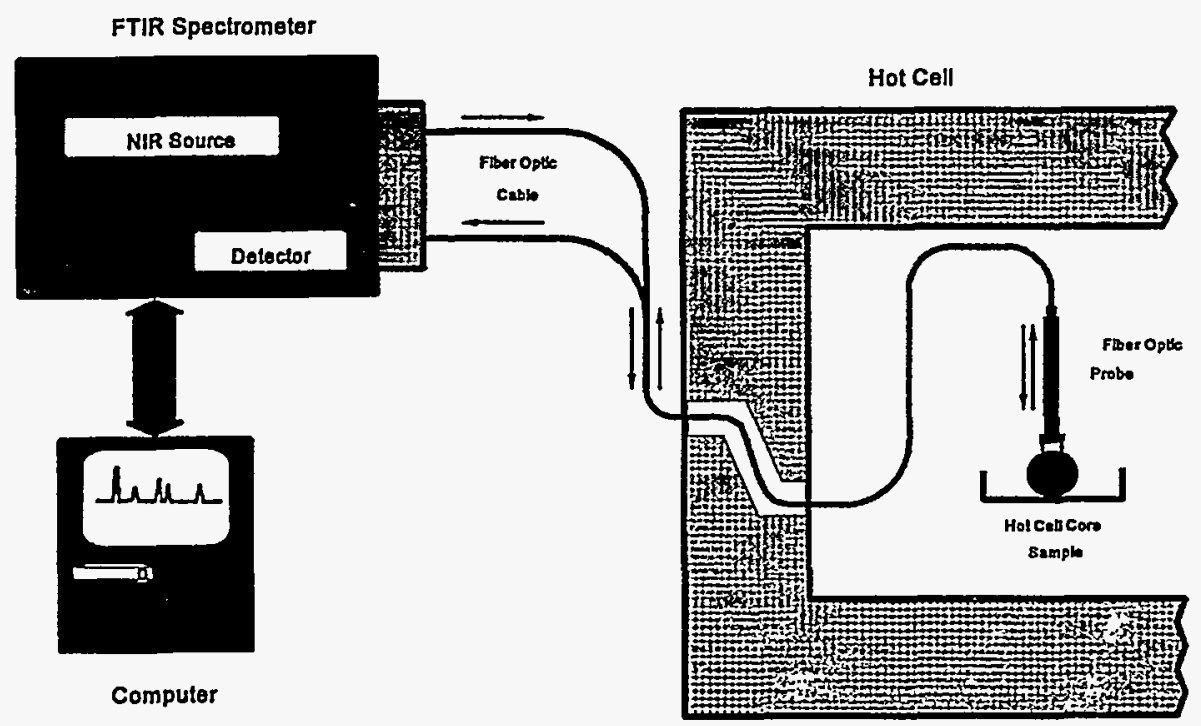

Figure 3. The hot cell near-infrared (NIR) system with a remote, chemical and radiation-hardened fiber-optic probe measures the water concentration of a high-level waste sample at Hanford.

The Fourier transform-infrared (FTIR) spectrophotometer, purchased from BioRad Fibreguide Industries, incorporates a dynamic interferometer alignment in a high-throughput 60-degree Michelson interferometer with:

spectral range between 10,000 to $3,300 \mathrm{~cm}^{-1}$,

$0.5 \mathrm{~cm}^{-1}$ resolution,

$\checkmark$ quartz-substrate beam splitter,

$\checkmark$ tungsten halogen lamp source, and

$\checkmark$ an indium-antimonide liquid-nitrogen cooled detector.

A typical analysis requires data recorded over a spectral range of 10,000 to $3,300 \mathrm{~cm}^{-1}$, the region that includes the 6,600 and $5,200 \mathrm{~cm}^{-1}$ water absorption peaks. 


\section{TECHNOLOGY DESCRIPTION}

\section{Remote Fiber-Optic Probe}

Comparison tests with simulant and real waste materials were used to select a fiber-optic probe design that was optimized for remote hot-cell application. The hot-cell fiber-optic cable is a 50-meter, bi-furcated cable composed of 40 input and 40 output optical fibers. The features of the fiber-optic cable are:

$\checkmark$ radiation-resistant, 100-um diameter silica core fibers (step-index) with doped silica cladding and a polyamide protective cover,

$\checkmark$ a polyethylene jacket that is chemical and radiation resistant.

- Longer (or shorter) cable lengths can be used with the current NIR system.

- The nickel-plated probe housing contains a unique optical design that reduces stray light and makes the probe insensitive to waste form. The probe was purchased from Axiom Analytical Incorporated.

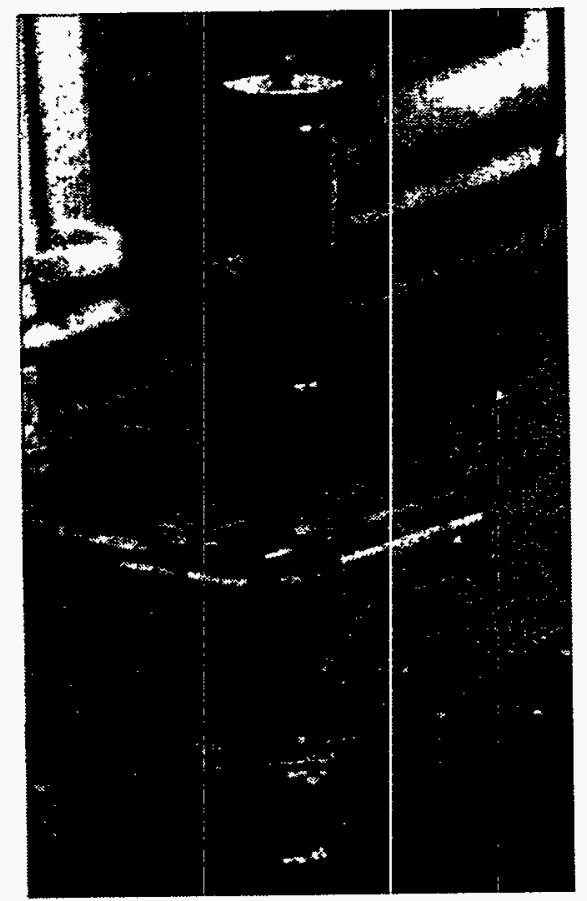

Figure 4. The NIR system's rugged fiber optic probe.

- The specifications of the probe include:

04 to $5 \mathrm{~mm}$ spot size, near-collimated beam,

$\checkmark$ flat response over a sample-to-probe distance variation of $6 \mathrm{~mm}$,

010 to 15 degree angled output lens and sapphire window to reduce stray light, and

$\checkmark$ an apertured input lens (small on-axis spot) to reduce stray light reflections into the detector fiber-optic channel. 


\section{TECHNOLOGY DESCRIPTION}

\section{continued}

\section{PLS-based Numerical Analysis}

The NIR system extracts water concentration data from a numerical method that is based on PLS analysis.

- All spectra are pre-processed by smoothing and "zero" shifting.

- The pre-processing and PLS method were selected after comparison tests were completed with a number of options using the principal component regression (PCR) model.

- The PLS software was part of the package included in the Biorad spectrophotometer hardware purchase.

- The chosen PLS model demonstrated a standard deviation of $1.57 \mathrm{wt} \%$ as compared with 1.89 wt\% for the best PCR model.

Additional discussion of the PLS numerical analysis is included in Section 3 under performance issues. 


\section{PERFORMANCE}

\section{Demonstration Overview}

The performance of NIR spectroscopy for determining water concentration and materials homogeneity is demonstrated by two applications described below. The first application illustrates the potential for ascertaining moisture gradient in a tank simulant material, while the second application evaluates the potential for sensing similarities between tank wastes.

- The NIR methodology must provide precision and accuracy that is equivalent to the baseline technology. Data from TGA analyses of core segments were directly compared with data acquired with the NIR spectrometer inside the hot cell immediately after extrusion. In addition, aliquots were removed from the same spot on the core segment that was measured with the NIR spectrometer, and weight loss by oven heating was conducted.

\section{First Demonstration: Moisture Gradient in Settled Simulant}

- A small, cylindrical vessel of clear polyethylene was filled with simulant and used in an experiment to determine if moisture gradients would develop from the settling of tank wastes (Reich et al., 1995).

After excess water had been initially drained, this simulant-filled vessel was allowed to sit in a vertical position for over 1$1 / 2$ years. If water were to settle out due to gravity, there would be a moisture gradient in the vessel, and the water concentration would be greatest near the bottom of the vessel.

- The NIR system was used to analyze the water concentration of the simulant by "looking" through the wall of the clear polyethylene vessel.

$\checkmark$ The spectra recorded are shown in Figure 5 (recorded at 0.25 inch vertical increments).

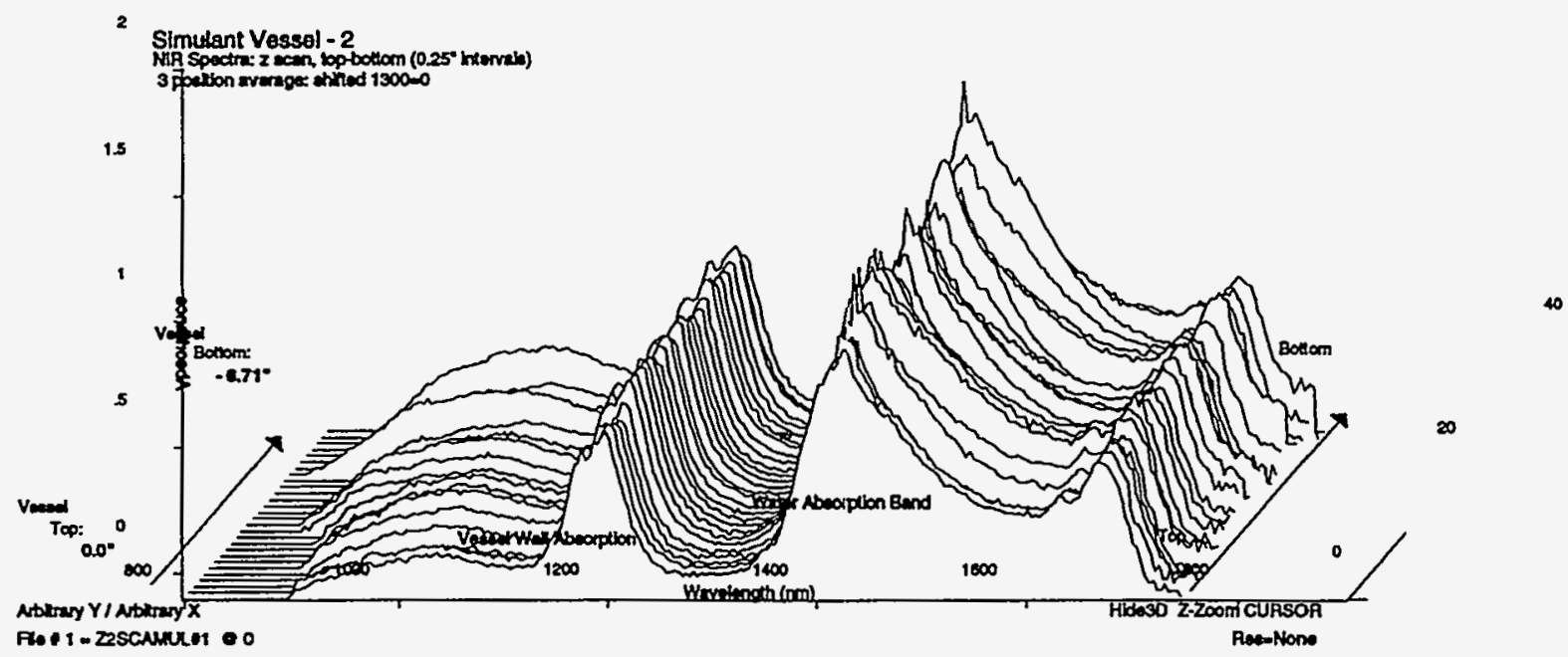

Figure 5. NIR spectra were obtained at 0.25 inch elevations in the simulant settling test vessel.

The sampling positions are shown as the $\mathrm{z}$-axis in the isometric graph.

The NIR spectral range $\left(12,500 \mathrm{~cm}^{-1}\right.$ to $5,600 \mathrm{~cm}^{-1}$, or $800 \mathrm{~nm}$ to $\left.1800 \mathrm{~nm}\right)$ includes only the $7,100 \mathrm{~cm}^{-1}(1400 \mathrm{~nm})$ water absorption band.

The lack of any spectral height variations for the $7,100 \mathrm{~cm}^{-1}(1400 \mathrm{~nm})$ absorption band in Figure 5 shows that water migration as a function of gravity is minimal.

$\checkmark$ Note that the stability of the NIR system can be assessed by the spectral amplitude and uniformity in the profile of the $\mathrm{C}-\mathrm{H}$ overtone band. 
- To aid in determining moisture gradient, spectra were recorded from simulants with known water concentrations.

$\checkmark$ Figure 6 illustrates what would be observable if a large, continuous moisture gradient existed in the filled vessel. These spectra are from simulant samples with water concentrations ranging from $0.6 \mathrm{wt} \%$ to $32.3 \mathrm{wt} \%$.

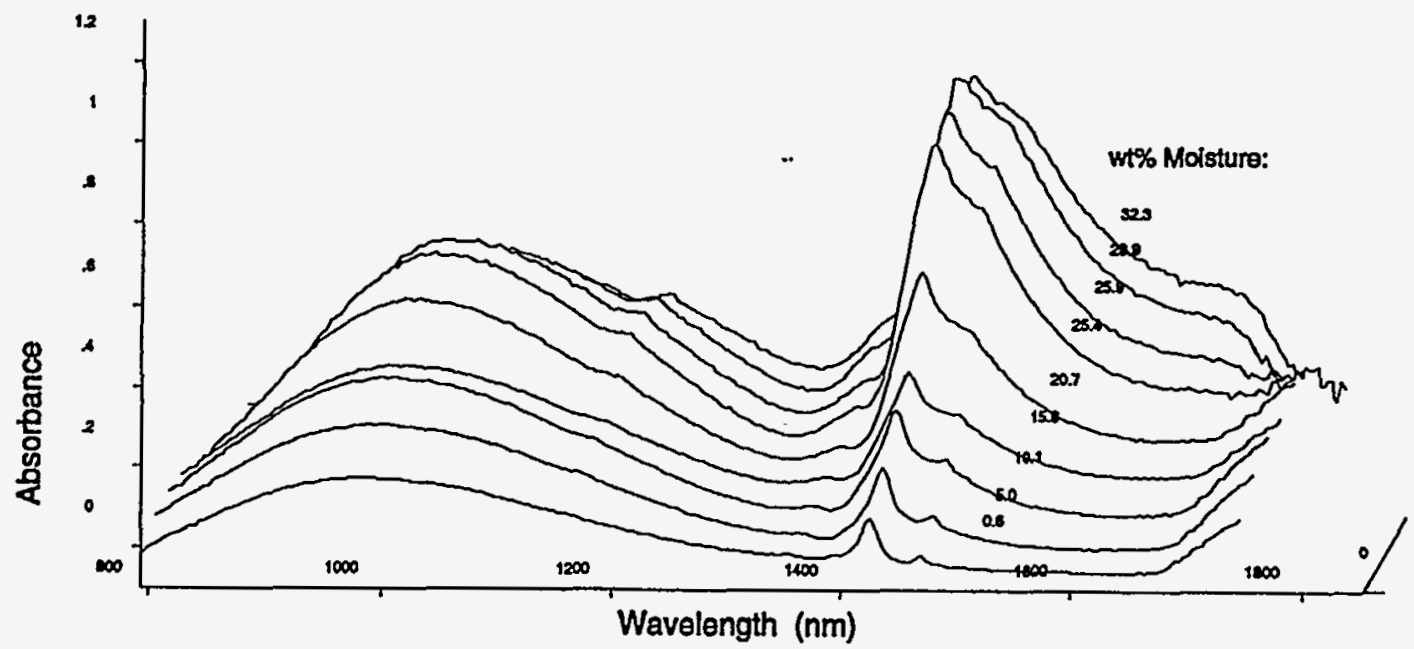

Figure 6. Calibration spectra from simulant samples show water concentration ranging from 0.6 to $32.3 \mathrm{wt} \%$.

$\checkmark$ Note that the polyethylene $\mathrm{C}-\mathrm{H}$ overtone is not present, as these measurements were made directly from the simulant surface.

0 The calibration samples were prepared by first drying the simulants and adding known amounts of water to dried aliquots. After spectra collection, the water concentration of each sample was then verified by thermogravimetric methods.

- The homogeneity of the simulant samples' water concentration is more visible in Figure 7, which shows spectral residuals, or differences. The spectral residuals were obtained by using a reference of one recorded measurement.

The absorption band, centered around $8,300 \mathrm{~cm}^{-1}(1200 \mathrm{~nm})$ in Figure 7, is the C-H overtone from the polyethylene vessel.

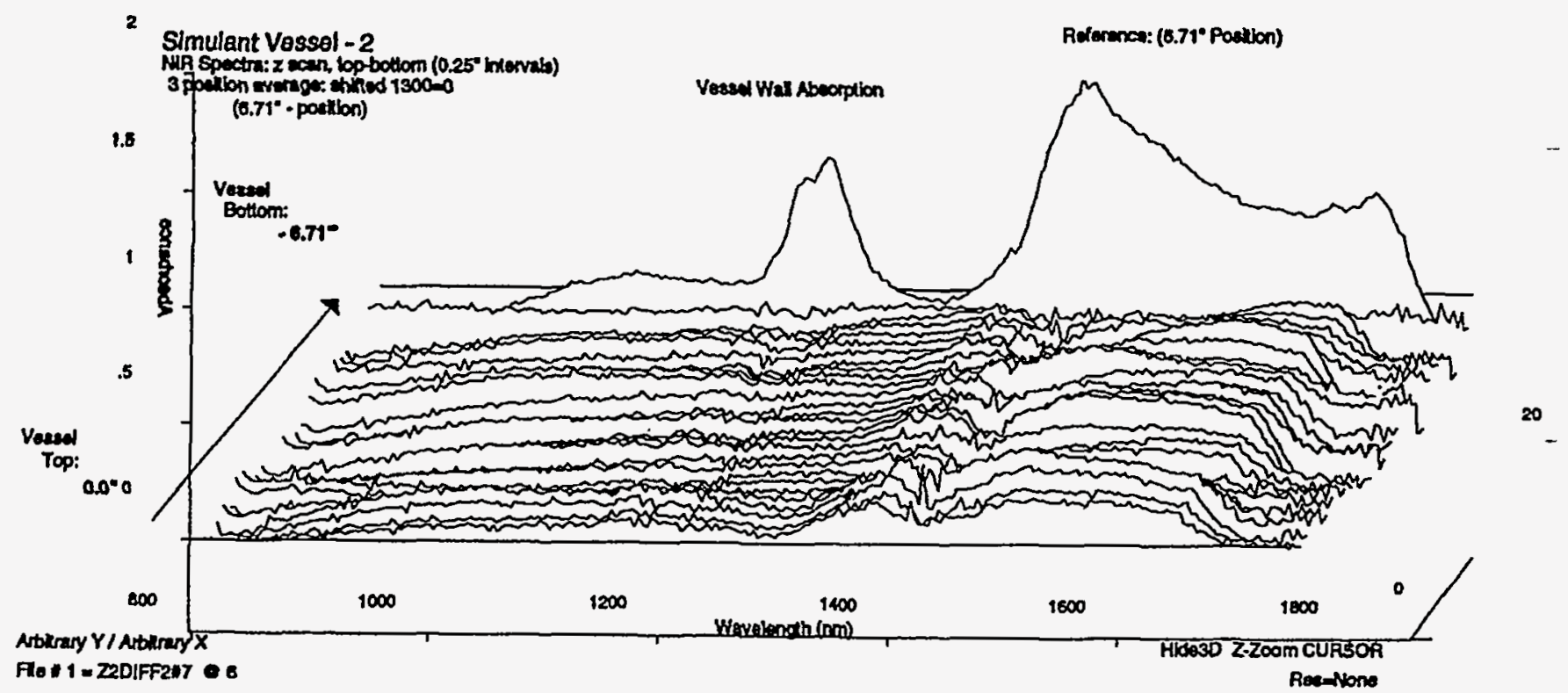

Figure 7. A representation of the differences, or residuals, among the samples. 


\section{Second Demonstration: Homogeneity of Tank Waste Core}

- The ability to indicate homogeneity within real materials was demonstrated using the NIR spectra obtained from tank core samples.

- Figure 8 shows NIR spectra that were obtained from nine different waste tank core samples using the NIR system. The samples were from wastes generally classified as tank slurries, which normally contain significant amounts of water.

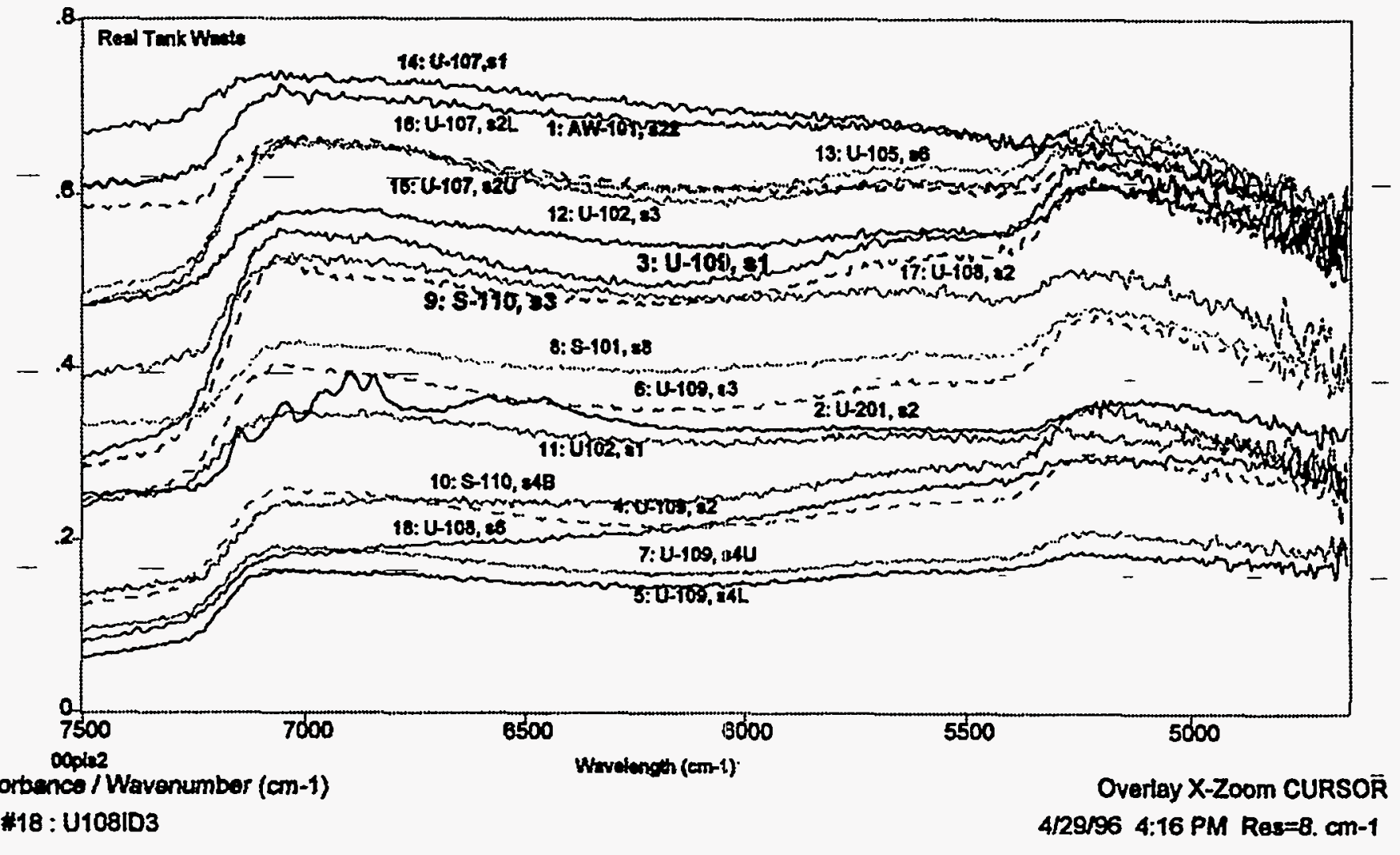

Figure 8. NIR spectra were recorded from core samples taken from nine different waste tanks with the NIR moisture monitor system.

0 The overall shape of the NIR spectra are the composite absorption bands from water overtones at $7,100 \mathrm{~cm}^{-1}(1400 \mathrm{~nm})$ and $5,300 \mathrm{~cm}^{-1}(1900 \mathrm{~nm})$ and from the overtones of organic and inorganic compounds that exhibit strong overtone absorption over the $7,700 \mathrm{~cm}^{-1}$ to $4,500 \mathrm{~cm}^{-1}(1300 \mathrm{~nm}$ to $2200 \mathrm{~nm})$ wavelength range. For example, the C-H stretch overtone band is centered around $8,300 \mathrm{~cm}^{-1}(1200 \mathrm{~nm})$.

- The spectra in Figure 8 were numerically analyzed using the PLS program. A single set of eigenvector spectra is calculated from the ensemble of spectra.

$\checkmark$ For each individual spectrum, a scaling constant, or a score coefficient, is then calculated for each of these common eigenvectors.

$\checkmark$ The process is iterative in that the eigenvectors and scores are modified until the composite error between the reconstructed spectrum and the original spectrum reach a minimum level.

$\checkmark$ Each spectrum can be reconstructed by summing the product of its scores times the common eigenvectors. Because eigenvectors are common for these reconstructed spectra, a comparison of spectra scores can be used as an indicator of similarity or homogeneity between different spectra. 

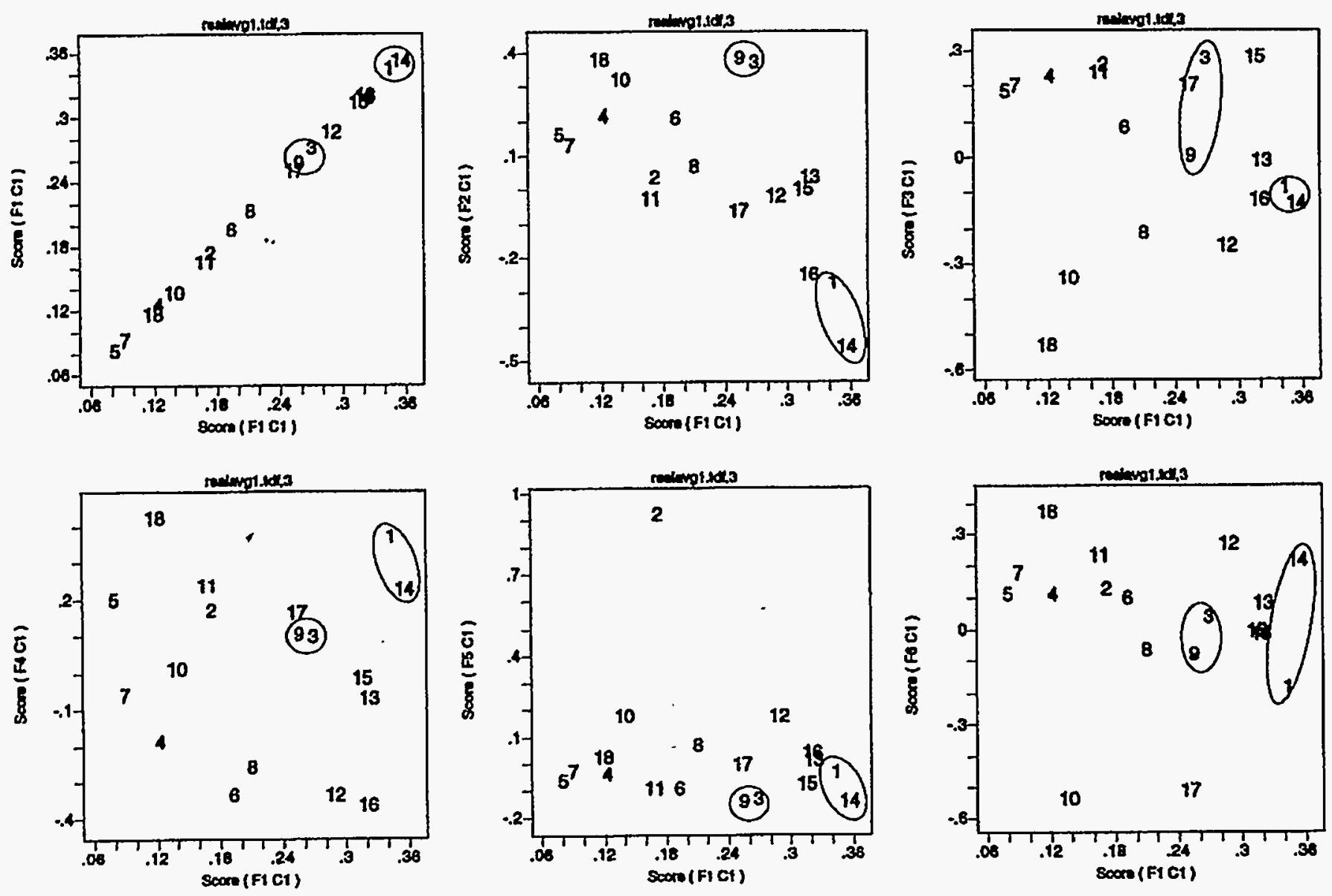

Figure 9. Eigenvector scores were derived from the PLS model analysis of spectra from the tank waste cores.

The $x$-axis = eigenvector $\# 1$; $y$-axiz = \#1 through \#6 eigenvectors.

- Figure 9 compares six eigenvector scores for the tank waste spectra in Figure 8.

0 In each plot, the $x$-axis shows the \#1 eigenvector score, while the $y$-axis is the \#1 through \#6 eigenvector scores, starting with \#1 in the upper left corner and ending with \#6 in the lower right corner.

- Spectra that have a similar shape and magnitude over their total wavelength range will have score values that cluster together in each of these $x-y$ plots. The clustering or grouping of their scores is a direct indication of how similar or homogeneous the spectra are. Thus, the score clustering in Figure 9 can be used as an impartial test to determine similarities or differences among the spectra shown in Figure 8.

$\checkmark$ For example, Figure 9 shows \#3 (Tank U-109) and \#9 (Tank S-110) spectra should have similar amplitude and peak shapes, because all their scores are grouped in all the x-y plots. Comparison of spectrum \#3 (Tank U-109) and spectrum \#9 (Tank S-110) in Figure 8 shows the expected similar spectral shape between the two.

$\checkmark$ An examination of the historical waste inventory of Tanks U-109 and S-110 shows these spectra were obtained as direct waste transfers from Tank U-102 (Agnew 1995). The historical inventory record indicates Tank U-109 received a transfer from U-102 in the first quarter of 1977, while Tank S-110 received a transfer from Tank U-102 in the second quarter of 1977. These transfers were in the 100,000 to 300,000 gallon range. There is a probability the waste samples in Tank U-109 and Tank S-110 are of the same type and have a similar chemical makeup.

A similar homogeneity assessment can be made for spectrum \#1 (Tank AW-101) and spectrum \#14 (Tank U-107). 


\section{PERFORMANCE}

$\checkmark \quad$ Figure 9 also displays close clustering for spectrum \#5 (Tank U-109) and spectrum \#7 (Tank U-109). The similarity of these two spectra is not surprising, because these core samples are from adjacent levels in Tank U-109; their separation is estimated to be less than 25 centimeters apart.

$\checkmark$ In contrast, spectra \#18 (Tank U-108) and \#17 (Tank U-108); and spectra \#5 (Tank U-109) and \#14 (Tank U-107) show a wide spread, represented in Figure 9. Figure 8 shows there are significant off-set and shape differences between these spectral pairs, resulting in a spread of scores.

\section{Conclusions}

- TGA showed significant differences among duplicate measurements on some samples. The NIR did not appear to suffer the same shortcomings.

- Between 4 and 25 wt\% water, the NIR is reliable and consistent.

- The commercial fiber-optic cable and components of the NIR probe will survive in a highly basic, $\mathrm{pH}>12$, radioactive waste tank environment. No chemical or radiation damage has been observed for the probe and fiber-optic cable left in a hot cell for over nine months.

- The NIR reduces the time needed to obtain water-concentration data with errors comparable to the TGA method. 


\section{Technology Applicability}

The NIR system can be used for remote moisture sensing for many materials with a wide range ( 0 to over $50 \mathrm{wt} \%)$ of moisture levels and a wide range of physical characteristics, including:

0 optically opaque or transparent,

0 radioactive, caustic, or acidic materials, and

0 liquid or solid.

- The NIR system has been applied to measurements of DOE high-level radioactive waste tank samples. These wastes are particularly difficult to measure because of their wide variation in color (optical absorption), particle size, and physical state (saltcake to slurries).

- The NIR system uses a remote probe and provides a nearly instant water concentration value, which is applicable for on-line applications where real-time moisture data are required. Although free water in a sample is usually the dominant feature, the NIR system is also sensitive to water that is chemically bound to other chemical species in the sample.

\section{Competing Technologies}

The current Hanford Site baseline water measurement system is the thermogravimetric analysis (TGA) method, which uses weight loss as the basis for determining water content in waste samples.

- This technique is based on measuring the total weight loss of a sample as the temperature is increased at a programmed rate to a preprogrammed end point.

- Typical sample mass interrogated by this method is generally small (between 10 and $30 \mathrm{mg}$ ) relative to the weight of a typical core segment.

- The TGA technique assumes the analyzed sample is representative of an entire extruded core segment (approximately $500 \mathrm{~g}$ ) and that water concentration is constant before and during preparation of the sample for analysis.

- The TGA method does not measure the amount of water evolved during the heating process but rather measures total weight loss, which may result from evaporation of volatile organic compounds or breakdown of inorganic compounds with the expulsion of oxygenated compounds, or the evolution of other products from the heating process..

- The TGA method requires contact and manipulation of the radioactive wastes with risk of spread of contamination and exposure of personnel to ionizing radiation.

- The TGA method generates a significant amount of excess secondary waste, mixed waste that must be remuved and disposed.

- The TGA method is not an instantaneous, real-time measurement technique, and samples may experience water loss before the measurement can be initiated.

- Several other instrumental technologies, e.g., Karl Fisher titration moisture analyzers, have been evaluated for their capability to measure the water content of waste samples. Each of these methods has been demonstrated to have measurement limitations from a production facility perspective.

\section{Technology Maturity}

NIR absorption for measuring the water content of solids, liquids, and gases is a widely known technique.

- Water absorption bands normally dominate the infrared and NIR optical regions, making water an adverse interferant in the use of spectral absorption for qualitative or quantitative measurement of other chemical species.

- The development of numerical analysis software; high-efficiency, room temperature NIR optical detectors; and rugged optical fibers have opened opportunities for many commercial applications. These applications include water analysis in flour, cookie dough, tobacco, paper production lines, nuclear fuel powders, and other production line products. In fact, an NIRbased system is currently a standard method for measuring water concentration in unprocessed grain.

- NRR-based systems for moisture sensing in relatively benign production environments are currently commercially available. However, commercial systems for remote sensing in adverse chemical and radioactive environments are not readily available. 


\section{SECTION 5}

\section{cost}

\section{Introduction}

Cost data presented below are derived from experience in the purchase of capital equipment to provide both the capability and the capacity to meet the anticipated work load.

- Costs for the NIR system for production measurements are shown below.

- Current systems are in place; and therefore, replacement costs are estimated to maintain reliability of the capacity. When replacement of this unit is required, the cost is expected to be considerably less, because this unit was purchased with considerable excess capability to perform quantitative analysis of several other analytes besides water. These capabilities are not required for the current use.

\section{Capital Costs}

The following table compares capital costs of instruments currently required to meet the laboratory's work load demands.

- Cost data clearly show NIR measurements can provide the required data at less expense than multiple TGA units. One NIR instrument can measure water concentration in samples received at the Hanford Site. Data collection is sufficiently rapid that multiple instruments for the estimated 15-sample-a-week capacity are not required. An instrument for backup is good laboratory practice but not required.

\begin{tabular}{|lcc|}
\hline \multicolumn{3}{|c|}{ Table 1. Capital Cost Comparison Table (\$K) } \\
\hline & Initial Cost & Replacement Cost \\
\hline NIR & 125 & 45 \\
\hline TGA & $180^{2}$ & $150^{2}$ \\
\hline TGA-IR & $120 \mathrm{ea}^{3}$ & $100 \mathrm{ea}^{3}$ \\
\hline
\end{tabular}

1 TGA with infrared off-gas analyzer suffers from same small sample size as previous analyzer systems.

2 Currently, three TGA systems are actively maintained to provide capacity with an additional unit as backup.

${ }^{3}$ Replacement of all TGA systems with this capability is not planned due to increased labor costs for evaluation of data.

\section{Operating Costs}

The table below provides a cost estimate to perform water measurements on highly radioactive samples. These costs are presented in hours and dollars, based on FY 1996 costs.

- These estimates assume multiple samples will provide efficiencies of operation, such as batching samples, etc. Continuous operation will reduce to a minimum the ratio of quality control samples to actual samples.

- These estimates do not account for reduced exposure of personnel to ionizing radiation. Worker exposure to contamination is a significant concern with the baseline TGA method.

\begin{tabular}{|lcccc|}
\hline \multicolumn{5}{|c|}{ Table 2. Operating Cost Comparison Table } \\
\hline & Hours per analysis & $\$$ per analysis & $\begin{array}{c}\text { Assume 15- sample } \\
\text { week average }\end{array}$ & Annual cost ${ }^{4}$ \\
\hline NIR & 1.0 & $\$ 60^{3}$ & $\$ 0.9 \mathrm{~K}$ & N/A \\
\hline TGA & $4.0^{1}$ & $\$ 250$ & $\$ 3.8 \mathrm{~K}$ & $\$ 99 \mathrm{~K}$ \\
\hline TGA-IR & 5.0 (est) $^{2}$ & $\$ 300$ (est) & $\$ 4.5 \mathrm{~K}$ (est) & $\$ 187 \mathrm{~K}$ \\
\hline
\end{tabular}


' Time includes preparing the sample, performing analysis, and interpreting data.

${ }^{2}$ This is a new instrumental technique and is not fully routine. Additional cost is necessary for interpreting $\mathbb{R}$ spectra in addition to sample handling and analysis.

${ }^{3}$ Correlation between dollars and hours is inconsistent, because different labor rates are used for exempt chemists and bargaining unit chemical technologists.

4 Values represent differences between annual cost by the methods used and NIR as the baseline.

\section{Cost Summary}

The comparison of NIR to TGA shows a clear reduction in capital costs and a large reduction in operating costs. An annual savings of at least $\$ 100 \mathrm{~K}$ in operating costs can be expected from the substitution of NIR for the accepted TGA methodology.

- Capital costs reflect the need for three TGA instruments, with a cost of $\$ 60 \mathrm{~K}$ each, to have sufficient capacity available to meet the workload demands on the laboratory. The current assumption is that the normal TGA units would be used for routine analyses, while the TGA-infrared ( $(R)$ instrument would perform analyses when anomalies were evident in the TGA data. The additional capital, operating costs, and complexity of operation make the TGA-IR measurement labor intensive. The workload on this instrument is expected to be minimal; although when the capability is required, it will be used.

Operating costs are directly related to personnel time expended on removing sample aliquots from the hot cell, loading the TGA sample pan, setting up operating parameters on the instrument, and evaluating the resulting data.

- The NIR eliminates the need for removing samples from the hot cell and loading the sample into the TGA instrument - the two most time-consuming steps in the TGA measurement process. A small cost factor is included in the above table for decontamination of work areas.

These costs do not consider the quality of information made available by the various techniques. The NIR measures water concentration, whereas both TGA and oven measurements are based on total weight loss as a sample is heated. The TGA-IR also provides water concentration but with a significant cost in time expended by chemists interpreting data. Data in the table include an estimate of time required for analyses that are rerun for imprecision in results; the data cannot estimate lack of quality for other reasons, e.g., presence of other volatile components. 


\section{REGULATORY/POLICY ISSUES}

\section{Regulatory Considerations}

The NIR system uses a low-power light source that does not require special controls or permitting for use. No special permitting is required for excitation source energy or for signal energy output. Samples remain within the hot cell rather than being loaded out for analyses in fume hood laboratory operations.

\section{Safety, Risks, Benefits and Community Reaction}

\section{Safety Risks}

By performing the measurement entirely within the hot cell, risk is significantly reduced for the spread of radioactive contamination, exposure of personnel to ionizing radiation, and inhalation of radionuclide-contaminated particulates. Baseline technology requires direct samples to be removed from the hot cell and analyzed. The potential for spills and exposure to the above risks is always present when these operations are performed.

Training personnel for operating the NIR and TGA-IR instruments and evaluating resulting data is equivalent with regard to time and prior experience. No additional expertise is necessary for the hot cell technologists to operate the NIR probe. The role of Radiological Control Technicians is reduced slightly by the reduced number of TGA aliquots removed from the hot cell.

\section{Environmental Impacts}

- The NIR system allows the sample to remain inside the hot cell, where containment is complete and hazards to workers and the workplace is miniscule. The NIR, therefore, provides additional measures of safety to workers and the workplace over the baseline technology.

- The NIR system requires minimal space. The probe requires approximately 30 by 30 centimeters inside the hot cell, and the spectrometer can be placed on a desk out of the traffic pattern. A cable, less than two centimeters in diameter and approximately 30 meters long, connects the probe and spectrometer. (The cable can be as long as the measurement area dictates.) 


\section{SECTION 7}

\section{LESSONS LEARNED}

\section{Design Issues}

- Simulants lack some important chemical constituents, including radionuclides, that have a significant impact in the NIR probe's optical band. Actual waste materials are required to complete final design and testing.

- The partial least squares (PLS) modeling methods need simulants that are representative of the physical, optical, and moisture ranges of the wastes that are to be measured with the NIR moisture probe.

- A fiber-optic probe can be designed with minimal sensitivity with respect to the probe-to-sample distance (lift-off) variation. The NIR probe was designed with a lift-off range of $+1-3 \mathrm{~mm}$, allowing the probe to be remotely positioned and handled with the hot-cell manipulators.

- The NIR probe exhibited some sensitivity to variations in sample surface height. It was necessary to flatten the sample area to get reproducible spectral data.

- Safe operations require that the hot-cell technologist be able to see the sample and the bottom of the probe. The viewing windows of a hot cell are normally sufficient for placing and using the probe to make water measurements. The probe was fabricated with stand-off pins attached to the case, which provides a positive non-contact distance from the sample being interrogated. The pins contact the sample, and this keeps the probe's optical window from contacting the sample. This noncontact configuration eliminates the need to decontaminate the optical window between sample measurements and reduces the probability of cross contamination between samples causing erroneous analytical results.

\section{Implementation Considerations}

- The major issue for acceptance of the technology is presentation of comparative data to demonstrate reliability of the NIR system to the Safety Program offices at Hanford.

\section{Needs for Future Development}

- To demonstrate sensitivity levels to organic chemicals, the NIR system needs to be evaluated with tank waste containing organic species.

- A probe design that compensates for optical scattering due to chemical and physical changes is needed for an in-situ, tank-deployable moisture system. 


\section{APPENDIX A}

\section{REFERENCES}

Agnew, S.F., R.A. Corbin, T.B. Duran, K.A. Jurgensen, T.P. Ortiz, and B.L. Young, 1995, Waste Status and Transaction Record Summary (WASTRS), WHC-SD-WM-TI-614, Rev. 1, Los Alamos National Laboratory, Los Alamos, New Mexico.

Babad, H., J.W. Hunt, and K.S. Redus, 1995, Tank Safety Screening Data Quality Objective, WHC-SD-WM-SP-004, Rev. 1, Westinghouse Hanford Company, Richland, Washington.

Postma, A.K., J.E. Meacham, G.S. Barney, G.L. Borsheim, R.J. Cash, M.D. Cripen, D.R. Dickinson, J.M. Grigsby, D.W. Jeppson, M. Kummerer, J.M. McLaren, C.S. Simmons, and B.C. Simmons, 1994, Ferrocyanide Safety Program: Safety Criteria for Ferrocyanide Watch List Tanks, WHC-EP-0691, Westinghouse Hanford Company, Richland, Washington.

Reich, F.R., R.E. Johnson, B.L. Philipp, J.B. Duncan, and G.L. Schutzenhofer, 1994, Summary of Fiscal Year 1994 NearInfrared Spectroscopy Moisture Activities, WHC-EP-0839, Rev 0, Westinghouse Hanford Company, Richland, Washington.

Reich, F.R., T.V. Rebagay, D.A. Dodd, T. Lopez, and J.K. Watts, 1995, Summary of FY-95 NIR Moisture Measurement Development and Implementation Activities, WHC-SD-WM-RPT-109, Rev. 0, Westinghouse Hanford Company, Richland, Washington. 


\section{APPENDIX B}

\section{SITE DESCRIPTION}

The Federal government established the Hanford Site near Richland, Washington in 1943 to produce plutonium for national defense purposes. The Hanford Site occupies approximately 1,450 square kilometers of land north of Richland. The production mission ended at the Hanford Site in 1988. The current Hanford Site mission is waste management and environmental restoration, which includes programs to manage and dispose of radioactive, hazardous, and mixed wastes that exist at the site.

At the Hanford Site, 149 single-shell tanks (SSTs) were constructed between 1944 and 1964. These tanks received high-level radioactive waste until 1980. Waste in the SSTs consists of liquids, sludges, and saltcake (crystallized salts). Over the years, much of the liquid stored in SSTs has been evaporated or pumped to double shell tanks (DSTs). Twenty eight DSTs were constructed at the Hanford Site between 1970 and 1986. The DSTs are used to store liquid radioactive waste from the SSTs and various Hanford Site processes. The waste is partially segregated and stored in tanks based on composition, level of radioactivity, or origin. 